\title{
Design and Synthesis of Two Oxazine Derivatives Using Several Strategies
}

\author{
Figueroa-Valverde Lauro, ${ }^{1}$ Díaz-Cedillo Francisco, ${ }^{2}$ \\ Rosas-Nexticapa Marcela, ${ }^{3}$ García-Cervera Elodia, ${ }^{1}$ Pool-Gómez Eduardo, ${ }^{1}$ \\ López-Ramos María, ${ }^{1}$ Hau-Heredia Lenin, ${ }^{1}$ and Sarabia-Alcocer Betty ${ }^{4}$ \\ ${ }^{1}$ Laboratory of Pharmaco-Chemistry, Faculty of Chemical Biological Sciences, University Autonomous of Campeche, \\ Avenida Agustín Melgar s/n, Col Buenavista, 24039 San Francisco de Campeche, CAM, Mexico \\ ${ }^{2}$ Escuela Nacional de Ciencias Biológicas del Instituto Politécnico Nacional, Prol, Carpio y Plan de Ayala s/n, Col Santo Tomas, \\ 11340 Mexico, DF, Mexico \\ ${ }^{3}$ Facultad de Nutrición, Universidad Veracruzana, Médicos y Odontólogos s/n, 91010 Xalapa, \\ VER, Mexico \\ ${ }^{4}$ Faculty of Medicine, University Autonomous of Campeche, Avenida Patricio Trueba de Regil s/n, Col Lindavista, \\ 24090 San Francisco de Campeche, CAM, Mexico
}

Correspondence should be addressed to Figueroa-Valverde Lauro; lauro_1999@yahoo.com

Received 22 October 2013; Accepted 12 December 2013; Published 23 January 2014

Academic Editor: Tanaji Talele

Copyright (C) 2014 Figueroa-Valverde Lauro et al. This is an open access article distributed under the Creative Commons Attribution License, which permits unrestricted use, distribution, and reproduction in any medium, provided the original work is properly cited.

Several oxazine derivatives have been synthesized; nevertheless, expensive reagents and special conditions are required. Therefore, in this study, two oxazine derivatives (2-chloro-3-\{\{2-[-(3-chloro-2-oxo-cyclobutyl)-(2,3-dimethoxy-9,10-dihydrostrychnid-10yl)-amino]-ethyl\}-[1,5-dimethyl-4-(1H-naphtho[1,2-e][1,3-oxazin-2-yl)-2-phenyl-2,3-dihydro-1H-pyrazol-3-yl]-amino\}-cyclobutanone and 2-chloro-3-\{\{2-[(3-chloro-2-oxo-cyclobutyl)-(1,7,7-trimethyl-bicyclo[2.2.1]hept-2-yl)-amino]-ethyl $\}$-[1,5-dimethyl4-(1H-naphtho[1, 2-e][1,3] oxazin-2-yl)-2-phenyl-2,3-dihydro- $1 H$-pyrazol-3-yl]-amino\}-cyclobutanone) were synthesized using several strategies. The structure of compounds obtained was confirmed by elemental analysis, spectroscopy, and spectrometry data. In conclusion, the methods used offer some advantages such as good yields, simple procedure, low cost, and ease of workup.

\section{Introduction}

Oxazine derivatives are very important heterocyclic compounds with several biological activities $[1,2]$. Several years ago, some oxazine derivatives have been synthesized; for example, the synthesis of 1,2-dihydro-1-arylnaphtho[1,2-e][1, 3] oxazine-3-one using the three-component system ( $\beta$-naphthol, benzaldehyde, and urea) in presence of $\mathrm{HClO}_{4}-\mathrm{SiO}_{2}$ [3]. Other report [4] showed the preparation of dirithromycin (9-N-11-O-oxazine derivative) by condensation of 9(S)erythromycylamine with 2-(2-methoxy-ethoxy)acetaldehyde. Other studies showed the condensation of 2-naphthol with heteroarylaldehydes or substituted benzaldehydes in the presence of ammonia [5]. In addition, a study [6] showed the synthesis of 3,4-dihydro-3-substituted-2H-naphtho[2,1e] [1,3] oxazine derivatives catalyzed by zirconium (IV) chloride. Other data [7] showed the reaction of substituted aryl and heteroarylaldehydes to give a series of 8-bromo-1,3-diaryl-2,3-dihydro- $1 H$-naphth [1,2e][1,3] oxazines. Also an other oxazine derivative (1,3-diphenyl-1H-naphtho[1,2-e][1,3] oxazine) was developed by the reaction of $\mathrm{N}$-arylidene-1- $(\alpha-$ aminoarylbenzyl)-2-naphthol with iodobenzene diacetate [8]. All these experimental results show several procedures which are available for synthesis of several oxazine derivatives; nevertheless, expensive reagents and special conditions are required. Therefore, in this study two oxazine derivatives were synthesized using some strategies. 


\section{Experimental}

The $\mathrm{N}^{1}$-(2,3-dimethoxystrychnidin-10-yliden)-ethane-1,2diamine (7) was synthesized according to a previously reported method [9]. The other compounds evaluated in this study were purchased from Sigma-Aldrich Co. Ltd. The melting points for the different compounds were determined on an electrothermal (900 model). Infrared spectra (IR) were recorded using $\mathrm{KBr}$ pellets on a Perkin Elmer Lambda 40 spectrometer. ${ }^{1} \mathrm{H}$ and ${ }^{13} \mathrm{C}$ NMR spectra were recorded on a Varian VXR-300/5 FT NMR spectrometer at 300 and $75.4 \mathrm{MHz}$ in $\mathrm{CDCl}_{3}$ using TMS as internal standard. EIMS spectra were obtained with a Finnigan Trace GCPolaris Q. spectrometer. Elemental analysis data were acquired from a Perkin Elmer Ser. II CHNS/0 2400 elemental analyzer.

2.1. 1,5-Dimethyl-4-(1H-naphtho[1,2,e][1,3]oxazin-2-(3H)-yl)2-phenyl-1,2-dihydro-3H-pyrazol-3-one (3). A solution of naphthol $(100 \mathrm{mg}, 0.69 \mathrm{mmol})$ and 4 -aminoantipyrine (141 $\mathrm{mg}, 0.69 \mathrm{mmol})$ formaldehyde $(1 \mathrm{~mL})$ in $10 \mathrm{~mL}$ of methanol was stirred for $72 \mathrm{~h}$ at room temperature. The reaction mixture was evaporated to a smaller volume. After the mixture was diluted with water and extracted with chloroform. The organic phase was evaporated to dryness under reduced pressure; the residue was purified by crystallization from methanol: water $(3: 1)$ yielding $80 \%$ of product, m.p. $176-$ $178^{\circ} \mathrm{C}$; IR $\left(V_{\max }, \mathrm{cm}^{-1}\right): 1718,1228,1140 ;{ }^{1} \mathrm{H}$ NMR $(300 \mathrm{MHz}$, $\left.\mathrm{CDCl}_{3}\right) \delta_{\mathrm{H}}: 2.10(\mathrm{~s}, 3 \mathrm{H}), 2.80(\mathrm{~s}, 3 \mathrm{H}), 5.20-5.70(\mathrm{~m}, 4 \mathrm{H}), 7.01$ $(\mathrm{m}, 1 \mathrm{H}), 7.10(\mathrm{~m}, 1 \mathrm{H}), 7.30(\mathrm{~m}, 1 \mathrm{H}), 7.40(\mathrm{~m}, 2 \mathrm{H}), 7.44(\mathrm{~m}, 2 \mathrm{H})$, $7.58(\mathrm{~m}, 2 \mathrm{H}), 7.60-7.66(\mathrm{~m}, 3 \mathrm{H}) \mathrm{ppm} .{ }^{13} \mathrm{C}$ NMR $(75.4 \mathrm{MHz}$, $\left.\mathrm{CDCl}_{3}\right) \delta_{\mathrm{C}}: 15.02,34.20,47.42,81.88,110.12,110.20,118.22$, $120.90,123.26,126.30,126.42,127.90,128.11,128.25,128.40$, $133.84,133.90,134.18,134.38,151.80,166.30 \mathrm{ppm}$. EI-MS $m / z$ : $371.10\left(\mathrm{M}^{+} 10\right)$. Anal. Calcd., for $\mathrm{C}_{23} \mathrm{H}_{21} \mathrm{~N}_{3} \mathrm{O}_{2}$ : C, 74.39; $\mathrm{H}$, 5.70; N, 11.31; O, 8.61. Found: C, 74.36; H, 5.68.

2.2. N-1-[1,5-Dimethyl-4-(1H-naphtho[1,2-e][1,3]oxazin-2-yl)2-phenyl-1,2-dihydro-pyrazol-3-ylidene]-ethane-1,2-diamine

(4). A solution of $3(100 \mathrm{mg}, 0.27 \mathrm{mmol})$, ethylenediamine $(100 \mu \mathrm{L}, 1.50 \mathrm{mmol})$, and boric acid $(90 \mathrm{mg}, 1.45 \mathrm{mmol})$ in $10 \mathrm{~mL}$ of methanol was stirred for $72 \mathrm{~h}$ at room temperature. The reaction mixture was evaporated to a smaller volume, after the mixture was diluted with water and extracted with chloroform. The organic phase was evaporated to dryness under reduced pressure; the residue was purified by crystallization from methanol : water $(2: 1)$ yielding $62 \%$ of product, m.p. $102-104^{\circ} \mathrm{C}$; IR $\left(V_{\max }, \mathrm{cm}^{-1}\right)$ : 3382, 1228, 1140; ${ }^{1} \mathrm{H}$ NMR $\left(300 \mathrm{MHz}, \mathrm{CDCl}_{3}\right) \delta_{\mathrm{H}}: 1.10(\mathrm{~s}, 3 \mathrm{H}), 2.02(\mathrm{~s}, 3 \mathrm{H}), 3.06(\mathrm{~s}, 3 \mathrm{H})$, $3.18(\mathrm{t}, 2 \mathrm{H}, J=6.44 \mathrm{~Hz}), 3.70(\mathrm{t}, 2 \mathrm{H}, J=6.44 \mathrm{~Hz}), 4.34$ (broad, 2H), 5.20-5.76 (m, 4H), 6.98-7.04 (m, 3H), 7.30-7.48 $(\mathrm{m}, 3 \mathrm{H}) 7.52(\mathrm{~m}, 2 \mathrm{H}), 7.60-8.06(\mathrm{~m}, 3 \mathrm{H}) \mathrm{ppm} .{ }^{13} \mathrm{C} \mathrm{NMR}$ $\left(75.4 \mathrm{MHz}, \mathrm{CDCl}_{3}\right) \delta_{\mathrm{C}}: 15.50,34.70,40.24,47.24,54.92$, $81.38,105.28,109.66,119.30,121.68,121.80,123.30,123.90$, $126.30,126.80,127.91,128.40,131.90,133.80,134.18,139.50$, 142.60, 151.48 ppm. EI-MS m/z: $413.20\left(\mathrm{M}^{+} 10\right)$. Anal. Calcd. for $\mathrm{C}_{25} \mathrm{H}_{27} \mathrm{~N}_{5} \mathrm{O}$ : C, $72.61 ; \mathrm{H}, 6.58 ; \mathrm{N}, 16.94 ; \mathrm{O}, 3.87$. Found: $\mathrm{C}$, $72.60 ; \mathrm{H}, 6.56$.
2.3. N-[1,5-Dimethyl-4-(1H-naphtho[1,2-e][1,3]oxazin-2-yl)2-phenyl-1,2-dihydro-pyrazol-3-ylidene-2,3-dimethoxystrychnidin-10-ylidene-ethane-1,2-diamine (6)

Method A. A solution of 4 (100 mg, $0.24 \mathrm{mmol})$, brucine (95 $\mathrm{mg}, 0.24 \mathrm{mmol}$ ), and boric acid (30 mg, $0.48 \mathrm{mmol}$ ) in $10 \mathrm{~mL}$ of methanol was stirred for $72 \mathrm{~h}$ at room temperature. The reaction mixture was evaporated to a smaller volume, after the mixture was diluted with water and extracted with chloroform. The organic phase was evaporated to dryness under reduced pressure; the residue was purified by crystallization from methanol: water $(3: 2)$ yielding $80 \%$ of product, m.p. $158-160^{\circ} \mathrm{C}$; IR $\left(V_{\max }, \mathrm{cm}^{-1}\right)$ : $3322,1228,1140 ;{ }^{1} \mathrm{H}$ NMR $\left(300 \mathrm{MHz}, \mathrm{CDCl}_{3}\right) \delta_{\mathrm{H}}: 1.40-1.84(\mathrm{~m}, 3 \mathrm{H}), 2.02(\mathrm{~s}, 3 \mathrm{H}), 2.22-$ $3.10(\mathrm{~m}, 7 \mathrm{H}), 3.12(\mathrm{~s}, 3 \mathrm{H}), 3.26-3.69(\mathrm{~m}, 6 \mathrm{H}), 3.80(\mathrm{~s}, 3 \mathrm{H})$, $3.90(\mathrm{t}, 2 \mathrm{H}, J=6.54 \mathrm{~Hz}), 3.91(\mathrm{~s}, 3 \mathrm{H}), 3.92(\mathrm{t}, 2 \mathrm{H}, J=$ $6.54 \mathrm{~Hz}), 4.70(\mathrm{~m}, 1 \mathrm{H}), 5.20-5.78(\mathrm{~m}, 4 \mathrm{H}), 5.83-5.88(\mathrm{~m}, 2 \mathrm{H})$, 7.00-7.04 (m, 3H), 7.32-7.44 (m, 3H), $7.52(\mathrm{~m}, 2 \mathrm{H}), 7.55(\mathrm{~m}$, $1 \mathrm{H}), 7.60-8.04(\mathrm{~m}, 3 \mathrm{H}) \mathrm{ppm} .{ }^{13} \mathrm{C}$ NMR $\left(75.4 \mathrm{MHz}, \mathrm{CDCl}_{3}\right)$ $\delta_{\mathrm{C}}: 15.48,27.37,29.20,34.52,34.75,40.90,45.82,47.26,50.74$, $53.02,53.09,55.95,56.20,56.60,63.20,64.62,65.02,79.26$, $81.70,99.23,105.30,109.70,119.34,120.89,121.69,121.76,123.26$, $123.30,123.90,126.22,126.82,127.87,127.90,128.38,130.60$, $131.98,133.82,134.12,139.59,140.30,142.65,145.48,145.78$, 147.70, 151.50 ppm. EI-MS m/z: $789.38\left(\mathrm{M}^{+} 10\right)$. Anal. Calcd., for $\mathrm{C}_{48} \mathrm{H}_{51} \mathrm{~N}_{7} \mathrm{O}_{4}$ : C, 72.98; H, 6.51; N, 12.41; O, 8.10. Found: C, 72.96; H, 6.50 .

Method B. A solution of $3(100 \mathrm{mg}, 0.24 \mathrm{mmol})$, brucine derivative (105 $\mathrm{mg}, 0.24 \mathrm{mmol}$ ), and boric acid $(30 \mathrm{mg}$, $0.48 \mathrm{mmol}$ ) in $10 \mathrm{~mL}$ of methanol was stirred for $48 \mathrm{~h}$ at room temperature. The organic phase was evaporated to dryness under reduced pressure; the residue was purified by crystallization from methanol : water yielding $50 \%$ of product, m.p. $158-160{ }^{\circ} \mathrm{C} ;{ }^{1} \mathrm{H}$ and ${ }^{13} \mathrm{C}$ NMR data were similar to method $\mathrm{A}$ product.

2.4. 2-Chloro-3-\{\{2-[-(3-chloro-2-oxo-cyclobutyl)-(2,3-dimethoxy-9,10-dihydrostrychnid-10-yl)-amino]-ethyl\}-[1,5-dimethyl-4-(1H-naphtho[1,2-e][1,3oxazin-2-yl)-2-phenyl-2,3-dihydro-1H-Pyrazol-3-yl]-amino\}-cyclobutanone (9). A solution of $6(100 \mathrm{mg}, 0.10 \mathrm{mmol})$, chloroacetyl chloride $(35 \mu \mathrm{L}$, $0.44 \mathrm{mmol})$, and triethylamine $(60 \mu \mathrm{L}, 0.43 \mathrm{mmol})$ in $10 \mathrm{~mL}$ of methanol was stirred for $72 \mathrm{~h}$ at room temperature. The reaction mixture was evaporated to dryness under reduced pressure, after the mixture was diluted with water and extracted with chloroform. The organic phase was evaporated to dryness under reduced pressure; the residue was purified by crystallization from methanol : water $(3: 2)$ yielding $65 \%$ of product, m.p. $74-76^{\circ} \mathrm{C}$; IR $\left(V_{\max }, \mathrm{cm}^{-1}\right): 3410,1716,1228,1150$, $1140 ;{ }^{1} \mathrm{H}$ NMR $\left(300 \mathrm{MHz}, \mathrm{CDCl}_{3}\right) \delta_{\mathrm{H}}: 1.12-1.46(\mathrm{~m}, 2 \mathrm{H}), 1.54$ $(\mathrm{m}, 2 \mathrm{H}), 1.85(\mathrm{~m}, 1 \mathrm{H}), 1.86-1.87(\mathrm{~m}, 2 \mathrm{H}), 1.96(\mathrm{~s}, 3 \mathrm{H}), 2.04-$ $2.70(\mathrm{~m}, 5 \mathrm{H}), 2.70(\mathrm{~s}, 3 \mathrm{H}), 2.82-2.86(\mathrm{~m}, 4 \mathrm{H}), 2.87(\mathrm{~m}, 1 \mathrm{H})$, 2.90-3.42 (m, 3H), $3.54(\mathrm{~m}, 1 \mathrm{H}), 3.62-3.78(\mathrm{~m}, 3 \mathrm{H}), 3.80(\mathrm{~s}$, $3 \mathrm{H}), 3.90(\mathrm{~m}, 1 \mathrm{H}), 3.93(\mathrm{~s}, 3 \mathrm{H}), 3.98(\mathrm{~m}, 1 \mathrm{H}), 4.02(\mathrm{~m}, 1 \mathrm{H})$, $4.38(\mathrm{~m}, 1 \mathrm{H}), 4.62(\mathrm{~m}, 2 \mathrm{H}), 5.16-5.70(\mathrm{~m}, 4 \mathrm{H}), 5.88-5.97(\mathrm{~m}$, 2H), $6.90(\mathrm{~m}, 1 \mathrm{H}), 6.95(\mathrm{~m}, 1 \mathrm{H}), 7.00 \mathrm{~m}(\mathrm{~m}, 2 \mathrm{H}), 7.04(\mathrm{~m}, 1 \mathrm{H})$, 
<smiles>Oc1ccc2ccccc2c1</smiles>

(1)<smiles>Cc1c(N)c(=O)n(-c2ccccc2)n1C</smiles><smiles>Cc1c(N2COc3ccc4ccccc4c3C2)/c(=N/CCN)n(-c2ccccc2)n1C</smiles>

FIGURE 1: Synthesis of N-1-[1,5-dimethyl-4-(1H-naphtho[1,2-e][1,3] oxazin-2-yl)-2-phenyl-1,2-dihydro-pyrazol-3-ylidene]-ethane-1,2diamine (4). The first stage involves the reaction of naphthol (1) with 4-aminoantipyrine (2) to form the compound 1,5-dimethyl-4-(1Hnaphtho[1,2,e][1,3] oxazin-2-(3H)-yl)-2-phenyl-1,2-dihydro-3H-pyrazol-3-one (3) in presence of formaldehyde (i). The second stage was achieved by the reaction of 3 with ethylenediamine (ii) to form 4 .

$7.20(\mathrm{~m}, 1 \mathrm{H}), 7.30(\mathrm{~m}, 2 \mathrm{H}), 7.38-7.80(\mathrm{~m}, 5 \mathrm{H}) \mathrm{ppm} .{ }^{13} \mathrm{C} \mathrm{NMR}$ $\left(75.4 \mathrm{MHz}, \mathrm{CDCl}_{3}\right) \delta_{\mathrm{C}}: 15.02,27.34,31.88,32.40,32.66,34.28$, $34.32,40.86,46.50,47.72,50.30,50.38,50.72,50.74,55.95$, $56.20,56.29,62.90,63.20,64.16,66.32,70.72,71.00,73.10$, $74.29,78.30,82.20,96.38,100.40,108.30,109.20,113.70,114.66$, $118.60,119.30,119.90,121.06,121.60,123.28,126.30,127.80$, $127.90,128.11,128.40,132.70,132.90,134.89,140.30,143.40$, $146.30,146.78,150.54,203.44,204.20$ ppm. EI-MS m/z: 997.40 $\left(\mathrm{M}^{+} 10\right)$. Anal. Calcd. for $\mathrm{C}_{56} \mathrm{H}_{61} \mathrm{Cl}_{2} \mathrm{~N}_{7} \mathrm{O}_{6}: \mathrm{C}, 67.33 ; \mathrm{H}, 6.15 ; \mathrm{Cl}$, 7.10, N, 9.81; O, 9.61. Found: C, 67.30; H, 6.12.

2.5. N-[1,5-Dimethyl-4-(1H-naphtho[1,2-e][1,3]oxazin-2-yl)2-phenyl-1,2-dihydro-pyrazol-3-ylidene]- $N^{\prime}$-(1,7,7-trimethylbicyclo[2.2.1]hept-2-ylidene)ethane-1,2-diamine (11). A solution of 4 (100 mg, $0.24 \mathrm{mmol}), 1,7,7$-trimethylbicyclo[2.2.1] heptan-2-one $(40 \mathrm{mg}, 0.26 \mathrm{mmol})$, and boric acid $(30 \mathrm{mg}$, $0.48 \mathrm{mmol}$ ) in $10 \mathrm{~mL}$ of methanol was stirred for $48 \mathrm{~h}$ at room temperature. The reaction mixture was evaporated to a smaller volume, after the mixture was diluted with water and extracted with chloroform. The organic phase was evaporated to dryness under reduced pressure; the residue was purified by crystallization from methanol : water $(4: 1)$ yielding $75 \%$ of product, m.p. $90-92^{\circ} \mathrm{C}$; IR $\left(V_{\max }, \mathrm{cm}^{-1}\right): 3320,1228,1138 ;{ }^{1} \mathrm{H}$ NMR $\left(300 \mathrm{MHz}, \mathrm{CDCl}_{3}\right) \delta_{\mathrm{H}}: 0.80(\mathrm{~s}, 3 \mathrm{H}), 0.84(\mathrm{~s}, 6 \mathrm{H}), 1.12-$ $1.74(\mathrm{~m}, 4 \mathrm{H}), 2.04(\mathrm{~s}, 3 \mathrm{H}), 2.08-2.70(\mathrm{~m}, 3), 3.12(\mathrm{~s}, 3 \mathrm{H}), 3.72$ $(\mathrm{t}, 2 \mathrm{H}, J=6.54 \mathrm{~Hz}), 3.84(\mathrm{t}, 2 \mathrm{H}, J=6.54 \mathrm{~Hz}), 5.20-5.74(\mathrm{~m}$, $4 \mathrm{H}), 7.01-7.06(\mathrm{~m}, 3 \mathrm{H}), 7.32-7.46(\mathrm{~m}, 3 \mathrm{H}), 7.52(\mathrm{~m}, 2 \mathrm{H}), 7.60$ $8.04(\mathrm{~m}, 3 \mathrm{H}) \mathrm{ppm} .{ }^{13} \mathrm{C} \mathrm{NMR}\left(75.4 \mathrm{MHz}, \mathrm{CDCl}_{3}\right) \delta_{\mathrm{C}}: 11.20$, $15.48,19.04,19.40,27.40,31.18,34.70,38.66,43.70,47.24,47.40$, $49.90,52.50,53.35,81.72,105.31,109.60,119.38,121.66,121.78$, $123.30,123.88,126.22,126.80,127.90,128.40,131.98,133.86$, $134.10,139.57,142.62,151.50,172.02$ ppm. EI-MS $m / z: 547.30$ $\left(\mathrm{M}^{+} 10\right)$. Anal. Calcd. for $\mathrm{C}_{35} \mathrm{H}_{41} \mathrm{~N}_{5} \mathrm{O}: \mathrm{C}, 76.75 ; \mathrm{H}, 7.54 ; \mathrm{N}$, 12.79; O, 2.92. Found: C, 76.74; H, 7.52. 


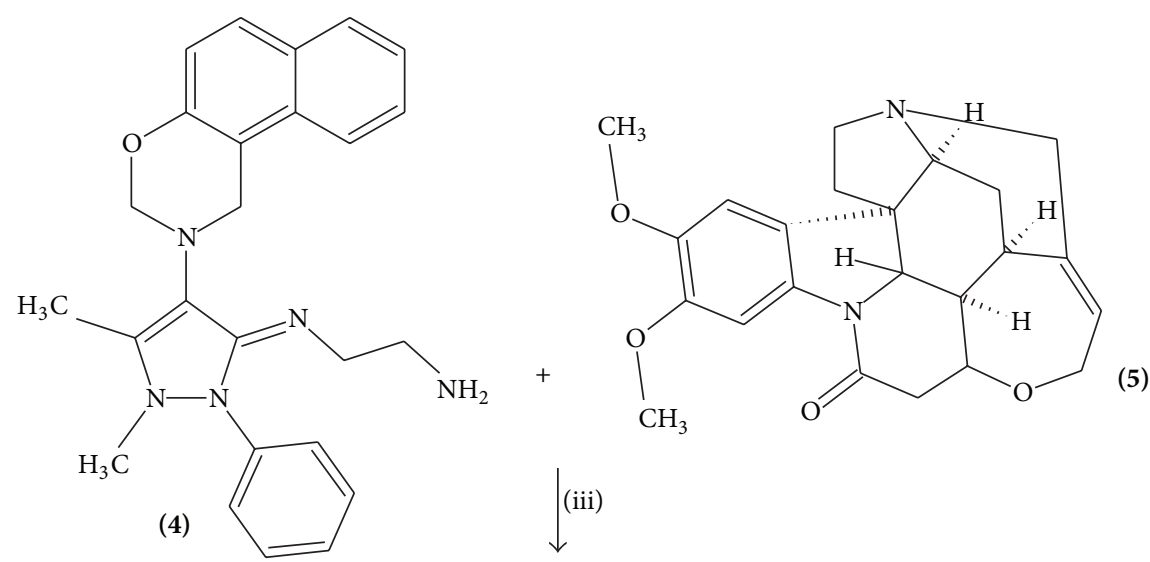

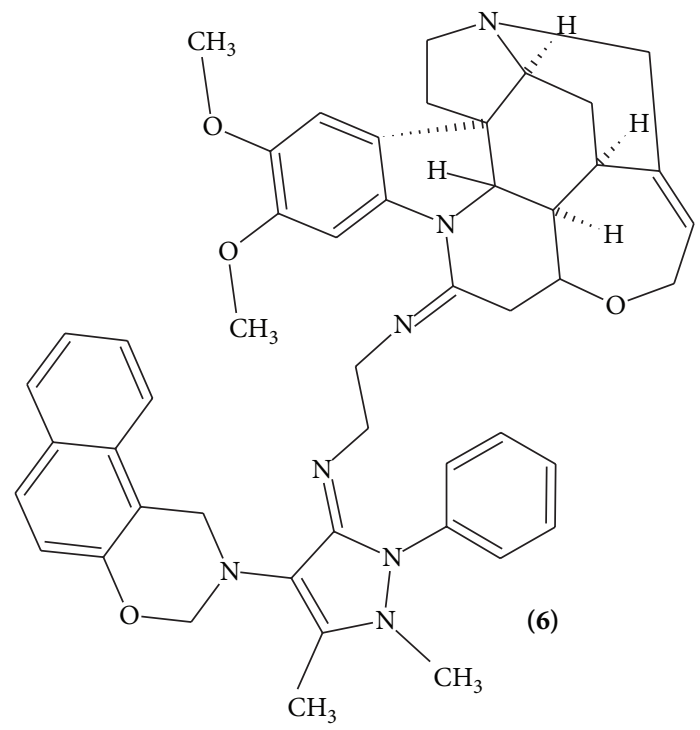

FIGURE 2: Synthesis of N-[1,5-dimethyl-4-(1H-naphtho[1,2-e][1,3]oxazin-2-yl)-2-phenyl-1,2-dihydro-pyrazol-3-ylidene]-2,3-dimethoxystrychnidin-10-ylidene-ethane-1,2-diamine (6). Reaction of N-1-[1,5-dimethyl-4-(1H-naphtho[1,2-e][1,3] oxazin-2-yl)-2-phenyl-1,2-dihydropyrazol-3-ylidene]-ethane-1,2-diamine (4) with brucine (5) to form the compound 6. iii: boric acid/rt.

2.6. 2-Chloro-3-\{\{2-[(3-chloro-2-oxo-cyclobutyl)-(1,7,7-trimethyl-bicyclo[2.2.1]hept-2-yl)-amino]-ethyl\}-[1,5-dimethyl4-(1H-naphtho[1,2-e][1,3]oxazin-2-yl)-2-phenyl-2,3-dihydro1H-pyrazol-3-yl]-amino $\}$-cyclobutanone (12). A solution of 11 (100 mg, $0.18 \mathrm{mmol})$, chloroacetyl chloride $(35 \mu \mathrm{L}, 0.44$ $\mathrm{mmol})$, and triethylamine $(60 \mu \mathrm{L}, 0.43 \mathrm{mmol})$ in $10 \mathrm{~mL}$ of methanol was stirred for $48 \mathrm{~h}$ at room temperature. The reaction mixture was evaporated to a smaller volume, after the mixture was diluted with water and extracted with chloroform. The organic phase was evaporated to dryness under reduced pressure; the residue was purified by crystallization from methanol: water $(2: 1)$ yielding $75 \%$ of product, m.p. 98-100 ${ }^{\circ}$; IR $\left(V_{\max }, \mathrm{cm}^{-1}\right): 1716,1228,1196,1138 ;{ }^{1} \mathrm{H}$ NMR $\left(300 \mathrm{MHz}_{\mathrm{CDCl}}\right) \delta_{\mathrm{H}}: 0.68(\mathrm{~s}, 3), 0.72(\mathrm{~s}, 3 \mathrm{H}), 0.81(\mathrm{~s}, 3 \mathrm{H})$, $1.12-1.28(\mathrm{~m}, 4 \mathrm{H}), 1.58(\mathrm{~m}, 1 \mathrm{H}), 1.68-1.70(\mathrm{~m}, 2 \mathrm{H}), 1.71(\mathrm{~m}$, $1 \mathrm{H}), 1.75(\mathrm{~m}, 1 \mathrm{H}), 1.86(\mathrm{~m}, 2 \mathrm{H}), 1.98(\mathrm{~s}, 3 \mathrm{H}), 1.99(\mathrm{~m}, 1 \mathrm{H}), 2.60$ $(\mathrm{m}, 1 \mathrm{H}), 2.62-2.68(\mathrm{t}, 2 \mathrm{H}, J=6.51 \mathrm{~Hz}), 2.74(\mathrm{~s}, 3 \mathrm{H}), 2.83-2.84$ $(\mathrm{t}, 2 \mathrm{H}, J=6.51 \mathrm{~Hz}), 3.64-4.04(\mathrm{~m}, 2 \mathrm{H}), 4.38(\mathrm{~m}, 1 \mathrm{H}), 4.62$ $(\mathrm{m}, 2 \mathrm{H}), 5.16-5.70(\mathrm{~m}, 4 \mathrm{H}), 6.90-7.00(\mathrm{~m}, 3 \mathrm{H}), 7.09(\mathrm{~m}, 1 \mathrm{H})$, $7.30(\mathrm{~m}, 2 \mathrm{H}), 7.38-7.78(\mathrm{~m}, 5 \mathrm{H}) \mathrm{ppm} .{ }^{13} \mathrm{C}$ NMR $(75.4 \mathrm{~Hz}$,
$\left.\mathrm{CDCl}_{3}\right) \delta_{\mathrm{C}}: 13.36,15.06,19.86,20.20,26.40,32.66,32.70$, $34.30,36.50,36.72,44.40,47.12,47.78,50.66,51.40,53.88$, $61.70,62.92,71.00,72.22,73.10,82.24,100.40,109.20,113.70$, $114.66,118.60,119.90,121.09,123.30,126.28,127.90,128.12$, $128.40,132.76,134.80,140.86,150.50,202.02,203.40 \mathrm{ppm}$. EI-MS m/z: $755.30\left(\mathrm{M}^{+} 10\right)$. Anal. Calcd. for $\mathrm{C}_{43} \mathrm{H}_{51} \mathrm{Cl}_{2} \mathrm{~N}_{5} \mathrm{O}_{3}$ : C, 68.24; H, 6.79; Cl, 9.37; N, 9.25; O, 6.34. Found: C, 68.20; $\mathrm{H}, 6.78$.

\section{Results and Discussion}

In this study were synthesized two oxazine derivatives using some strategies; it is important to mention that there are reports which indicate that condensation of naphthol with formaldehyde and amino groups result in naphthoxazines $[10,11]$. Therefore, in the first stage was synthesized the compound 1,5-dimethyl-4-(1H-naphtho[1,2,e][1,3] oxazin-2- $(3 H)$ yl)-2-phenyl-1,2-dihydro-3H-pyrazol-3-one (3) by the reaction of naphthol, 4-aminoantipyrine, and formaldehyde (Figure 1). The ${ }^{1} \mathrm{H}$ NMR spectrum of 3 show signals at 2.10 
<smiles>Cc1c(N2COc3ccc4ccccc4c3C2)c(=O)n(-c2ccccc2)n1C</smiles>

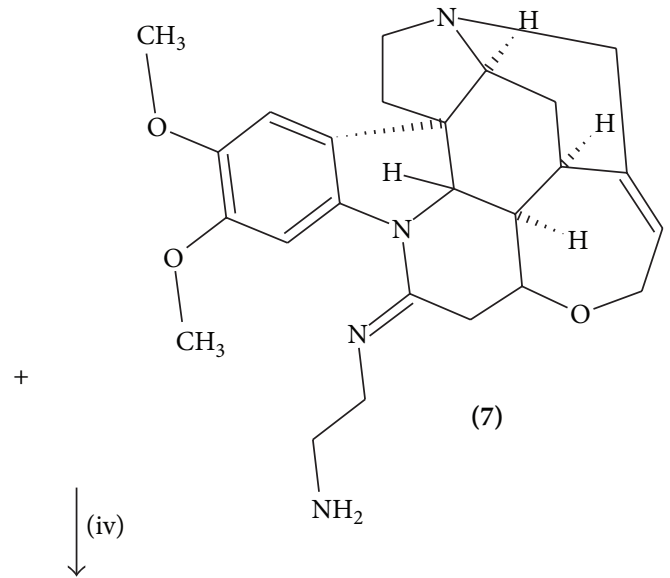

(3)

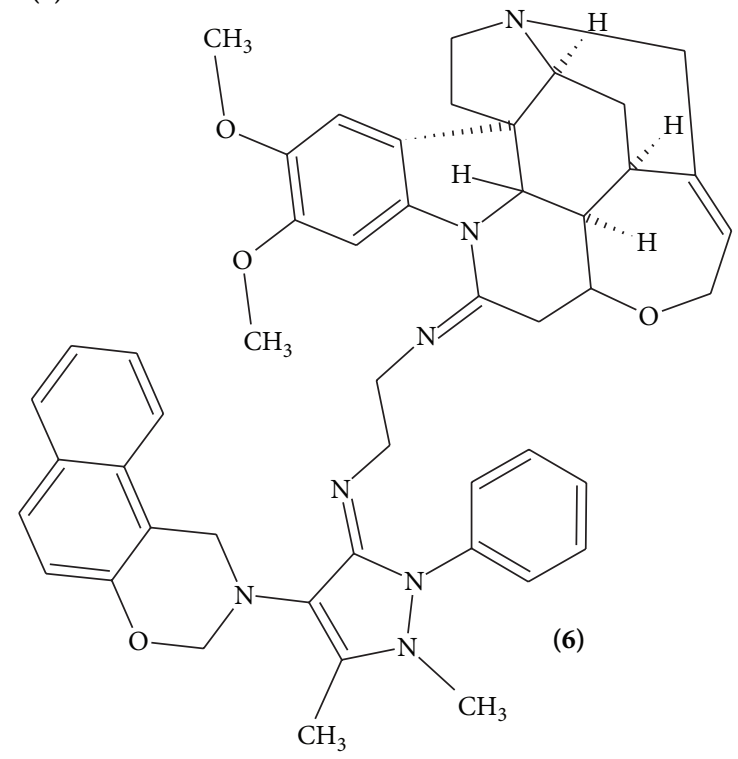

FIGURE 3: Synthesis of N-[1,5-dimethyl-4-(1H-naphtho[1,2-e] [1,3] oxazin-2-yl)-2-phenyl-1,2-dihydro-pyrazol-3-ylidene]-2,3-dimethoxystrychnidin-10-ylidene-ethane-1,2-diamine (6). Reaction of 1,5-dimethyl-4-(1H-naphtho[1,2,e][1,3] oxazin-2-(3H)-yl)-2-phenyl-1,2-dihydro$3 \mathrm{H}$-pyrazol-3-one (3) with $\mathrm{N}^{1}$-(2,3-dimethoxystrychnidin-10-yliden)-ethane-1,2-diamine (7) to form the compound $\mathbf{6}$. iv: boric acid/rt.

and 2.80 ppm for methyl groups; at 5.00-5.70 ppm for oxazine ring; at 7.01, 7.30, 7.44, and 7.60-7.66 ppm for naphthalene group bound to oxazine ring; at 7.10, 7.40, and $7.58 \mathrm{ppm}$ for phenyl group. The ${ }^{13} \mathrm{C}$ NMR spectrum of 3 contains peaks at 15.02 and 34.20 ppm for methyl groups; at 110.12 and 134.38 ppm for carbons involved in the cyclopentene ring; at 47.42 , $81.88,110.20$, and $151.80 \mathrm{ppm}$ for oxazine ring; at 118.52 $126.30,127.90,128.40$, and $133.90-134.18 \mathrm{ppm}$ for naphthalene group; at $126.42,128.11-128.25$, and 133.84 ppm for phenyl group; at $166.30 \mathrm{ppm}$ for ketone group. Finally, the presence of compound 3 was further confirmed from mass spectrum which showed a molecular ion at $\mathrm{m} / z$ 371.10.

The second stage was achieved by reaction of the compound 3 with ethylenediamine (Figure 1) resulting in imino bond formation involved in the compound 4 (N-1-[1,5dimethyl-4-(1H-naphtho[1,2-e] [1,3] oxazin-2-yl)-2-phenyl1,2-dihydro-pyrazol-3-ylidene]-ethane-1,2-diamine). Many procedures for the synthesis of imino groups are described in the literature [12-14]; nevertheless, in this study boric acid was used as a catalyst, because it is not an expensive reagent and no special conditions for its use are required [15]. The results of ${ }^{1} \mathrm{H}$ NMR spectrum of $\mathbf{4}$ show signals at 2.02 and 3.06 ppm for methyl groups; at 3.18 and 3.70 ppm for methylene groups involved in the arm bound to cyclopentene ring; at $4.34 \mathrm{ppm}$ for amino group; at $5.20-5.76 \mathrm{ppm}$ for oxazine ring; at 6.98-7.04 and 7.52 for phenyl group; at 7.30-7.48 and 7.60-8.06 ppm for naphthalene group. The ${ }^{13} \mathrm{C} N M R$ spectrum of 4 contains peaks at 15.50 and $34.70 \mathrm{ppm}$ for methyl groups; at 40.24 and 54.92 ppm for methylene groups involved in the arm bound to cyclopentene ring; at 47.24, $81.38-81.38,109.66$, and 151.48 ppm for oxazine ring; at 105.28 and $121.68 \mathrm{ppm}$ for methylene groups of cyclopentene ring; at $119.30,121.80-123.30,126.30,127.91-128.40$, and 133.80$134.18 \mathrm{ppm}$ for naphthalene group; at 123.90, 126.80, 131.90, 


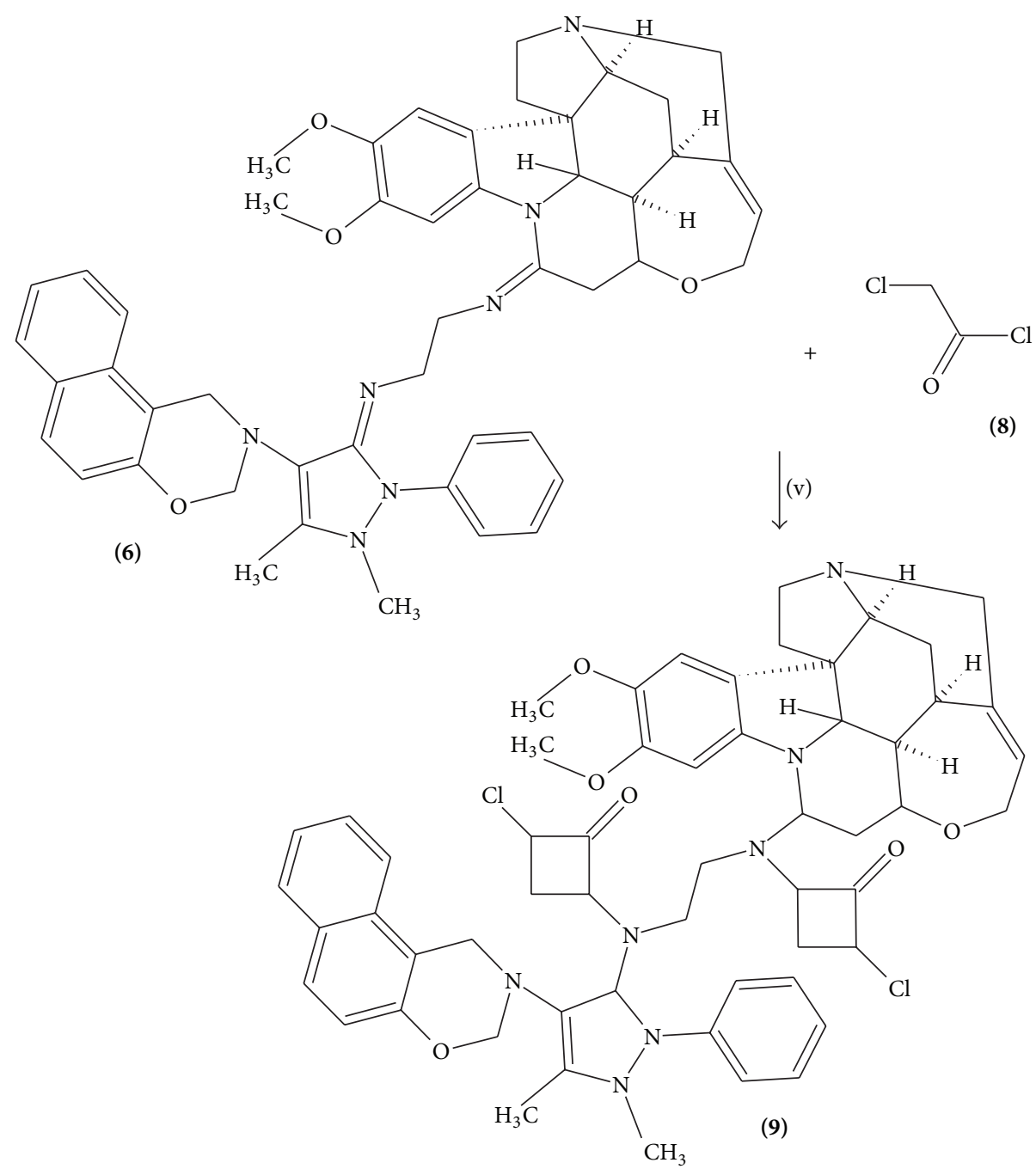

FIGURE 4: Synthesis of 2-chloro-3- $\{\{2$ - [-(3-chloro-2-oxo-cyclobutyl)-(2,3-dimethoxy-9,10-dihydrostrychnid-10-yl)-amino]-ethyl $\}$-[1,5dimethyl-4-(1H-naphtho[1,2-e][1,3oxazin-2-yl)-2-phenyl-2,3-dihydro-1H-pyrazol-3-yl]-amino\}-cyclobutanone (9). Reaction of $\mathrm{N}$-[1,5dimethyl-4-(1H-naphtho[1,2-e][1,3] oxazin-2-yl)-2-phenyl-1,2-dihydro-pyrazol-3-ylidene]-2,3-dimethoxystrychnidin-10-ylidene-ethane1,2-diamine (6) with chloroacetyl chloride (8) to form the compound $\mathbf{9}$. v: triethylamine/rt.

and $142.60 \mathrm{ppm}$ for phenyl group; at $139.50 \mathrm{ppm}$ for imino group. Finally, the presence of compound 4 was further confirmed from mass spectrum which showed a molecular ion at $m / z 413.20$.

In the third stage two different methods for synthesis of the oxazine-brucine derivative (6) were employed; the first step was achieved by reaction of the compound 4 with brucine to form the oxazine-brucine derivative (6) using boric acid as catalyst (method A, Figure 2). The results of ${ }^{1} \mathrm{H}$ NMR spectrum of $\mathbf{6}$ show signals at 2.02 and $3.12 \mathrm{ppm}$ for methyl groups bound to cyclopentene ring; at 1.40-1.84, 2.22-3.10, 3.26-3.69, 4.70, 5.83-5.88, and $7.55 \mathrm{ppm}$ for brucine nucleus; at 3.90 and 3.92 ppm for methylene groups involved in arm bound to cyclopentene ring; at 3.80-3.91 for methyl groups of brucine; at 5.20-5.78 for protons of oxazine ring; at 7.00-7.04 and 7.52 ppm for phenyl group; at 7.32-7.44 and 7.60-8.04 ppm for naphthalene group. The ${ }^{13} \mathrm{C}$ NMR spectrum of $\mathbf{6}$ contains peaks at 15.48 and 34.75 ppm for methyl groups bound to cyclopentene ring; at 27.37-34.52, 40.9045.82 , 56.20, 63.20-79.26, 99.23, 123.26, 127.87, 130.60, 140.30, and $145.48-147.70 \mathrm{ppm}$ for brucine nucleus; at 47.26, 81.70, 109.70-109.74, and 151.50 ppm for oxazine ring; at 55.02-55.09 for arm bound both imino groups; at 105.30, 121.69, and 139.59 ppm for cyclopentene ring; at 119.34, 121.76, 123.30$126.22,127.90-128.38$, and $133.82-134.12 \mathrm{ppm}$ for naphthalene group; at $123.90,126.82,131.98$, and 142.65 ppm for phenyl group; at 55.95 and 56.60 for methyl groups of brucine. Finally, the presence of compound 6 was further confirmed from mass spectrum which showed a molecular ion at $\mathrm{m} / z$ 789.38. The second step was achieved by reaction of the compound 3 with 7 to form the compound 6 using boric acid as catalyst (Figure 3). Similar ${ }^{1} \mathrm{H}$ and ${ }^{13} \mathrm{C}$ NMR data were obtained compared with method A product. However, it is noteworthy that with this method the yield was low as compared to method $\mathrm{A}$; this phenomenon possibly is due to time of reaction required with this methodology. 

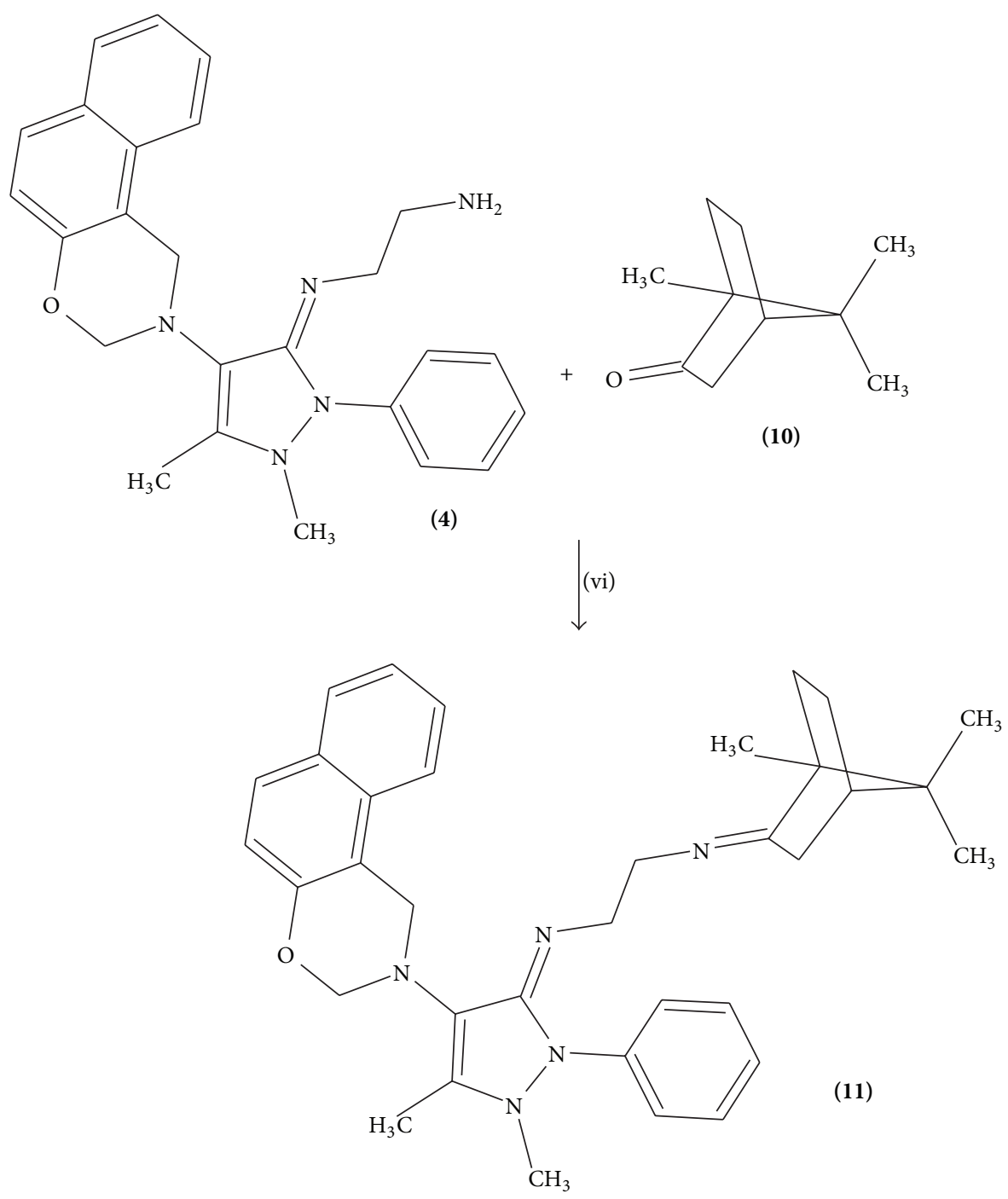

FIGURE 5: Synthesis of N-[1,5-dimethyl-4-(1H-naphtho[1,2-e][1,3] oxazin-2-yl)-2-phenyl-1,2-dihydro-pyrazol-3-ylidene]-N' ${ }^{\prime}$-(1,7,7-trimethylbicyclo[2.2.1] hept-2-ylidene)ethane-1,2-diamine (11). Reaction of N-1-[1,5-dimethyl-4-(1H-naphtho[1,2-e][1,3] oxazin-2-yl)-2-phenyl-1,2dihydro-pyrazol-3-ylidene]-ethane-1,2-diamine (4) with 1,7,7-trimethyl bicyclo[2.2.1] heptan-2-one (10) to form the compound 11. vi: boric acid/rt.

On the other hand, the compound 9 was synthesized (Figure 4); this compound has two chlorocyclobutane groups bound to both amino groups involved in their chemical structure. It is important to mention that there are several reports for preparation of chlorocyclobutenones using several techniques [16-19]; nevertheless, expensive reagents and special conditions are required. Therefore, in this study a new chlorocyclobutenone was formed in the chemical structure of 9 using chloroacetyl chloride in presence of triethylamine. The results of ${ }^{1} \mathrm{H}$ NMR spectrum of $\mathbf{9}$ show signals at 1.12$1.46,1.85,2.04-2.70,2.87-3.42,3.62-3.78,3.90,3.98,5.88-$ 5.97 , and $7.20 \mathrm{ppm}$ for brucine fragment; at $1.54,1.86-1.87$, $3.54,4.02$, and $4.62 \mathrm{ppm}$ for cyclobutanone groups; at 1.96 and $2.74 \mathrm{ppm}$ for methyl groups bound to cyclopentene ring; at 2.82-2.86 for methylene bound to both amino groups; at 3.80 and $3.93 \mathrm{ppm}$ for methyl groups of brucine fragment; at $4.38 \mathrm{ppm}$ for cyclopentene ring; at $5.16-5.70 \mathrm{ppm}$ for oxazine group; at $6.90-7.00$ and $7.30 \mathrm{ppm}$ for phenyl group; at 7.04 and $7.38-7.80 \mathrm{ppm}$ for naphthalene group. The ${ }^{13} \mathrm{C}$ NMR spectrum of 9 contains peaks at 15.02 and $34.28 \mathrm{ppm}$ for methyl groups bound to cyclopentene ring; at 27.34$31.88,34.32-46.50,50.72-50.74,56.20,63.20-66.32$, 74.29$78.30,96.38,108.30,121.06,132.90$, and $140.30-146.30 \mathrm{ppm}$ for brucine nucleus; at $32.40-32.66,62.90,70.72-71.00,203.44$, and $204.20 \mathrm{ppm}$ for cyclobutanone groups; at 47.72, 82.20, and $109.20 \mathrm{ppm}$ for oxazine group; at 50.30 and 50.38 for methylene groups bound to both amino groups; at 55.95 and $56.29 \mathrm{ppm}$ for methyl groups of brucine fragment; at 73.10, 100.40 , and $114.66 \mathrm{ppm}$ for cyclopentene ring; at 113.70, 119.30, 128.11 , and $146.78 \mathrm{ppm}$ for phenyl group; at 118.60, 119.90, $121.60-126.30,127.90,128.40-132.70,134.89$, and $150.54 \mathrm{ppm}$ for naphthalene group. Finally, the presence of compound 9 was further confirmed from mass spectrum which showed a molecular ion at $m / z 997.40$. 


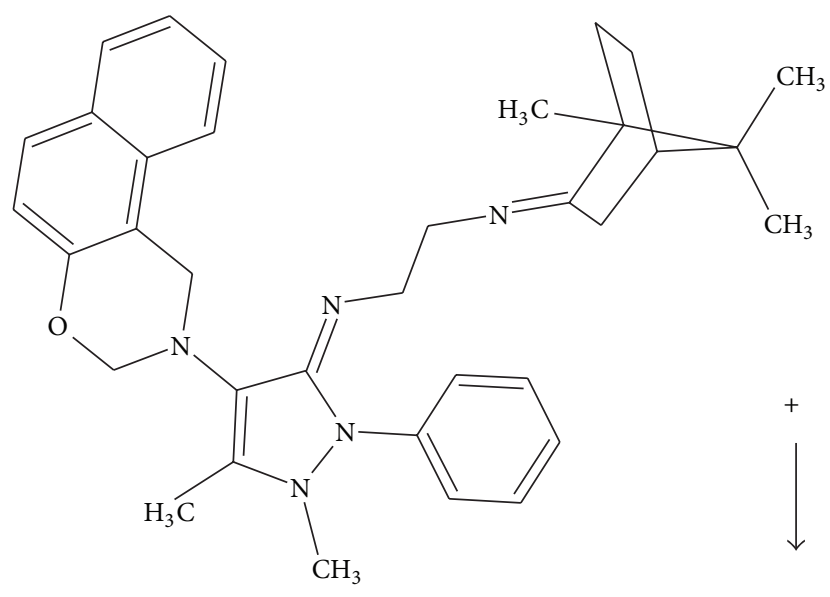

(11)

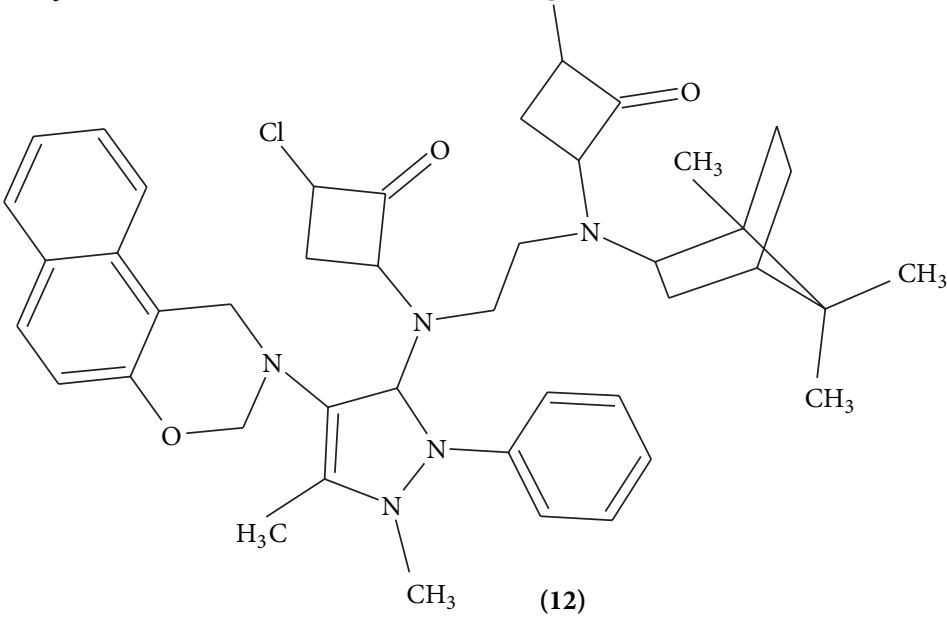

FiguRE 6: Synthesis of 2-chloro-3-\{\{2-[(3-chloro-2-oxo-cyclobutyl)-(1,7,7-trimethyl-bicyclo[2.2.1]hept-2-yl)-amino]-ethyl $\}$-[1,5-dimethyl4-(1H-naphtho[1,2-e][1,3] oxazin-2-yl)-2-phenyl-2,3-dihydro-1H-pyrazol-3-yl]-amino $\}$-cyclobutanone (12). Reaction of N-[1,5-dimethyl-4(1H-naphtho[1,2-e][1,3] oxazin-2-yl)-2-phenyl-1,2-dihydro-pyrazol-3-yli dene]-N'-(1,7,7-trimethyl-bicyclo[2.2.1]hept-2-ylidene)ethane-1,2diamine (11) with chloroacetyl chloride (8) to form the compound 12. v: triethylamine/rt.

The fourth stage was achieved by the reaction of $\mathbf{4}$ with 1,7,7-trimethylbicyclo[2.2.1] heptan-2-one to form the compound 11 using boric acid as catalyst (Figure 5). The ${ }^{1} \mathrm{H}$ NMR spectrum of 11 shows signals at 0.80 and $0.84 \mathrm{ppm}$ for methyl groups bound to bicyclic ring; at 1.12-1.74, 2.08$2.70 \mathrm{ppm}$ for protons of bicyclic ring; at 2.04 and $3.12 \mathrm{ppm}$ for methyl groups bound to cyclopentene ring; at 3.72 and $3.84 \mathrm{ppm}$ for methylene groups bound to both imino groups; at $5.20-5.74 \mathrm{ppm}$ for oxazine ring; at 7.01-7.06 and $7.52 \mathrm{ppm}$ for phenyl group; at 7.32-7.46 and 7.60-8.04 ppm for naphthalene group. The ${ }^{13} \mathrm{C}$ NMR spectrum of 11 contains peaks at 11.20 and $19.04-19.40 \mathrm{ppm}$ for methyl groups bound to bicyclic ring; at 15.48 and $34.70 \mathrm{ppm}$ for methyl groups bound to cyclopentene ring; at 27.40, 31.18, 38.66-43.70, 47.40, 49.90, and $172.02 \mathrm{ppm}$ for bicyclic ring; at 47.24, 81.72, and 109.60 ppm for carbons involved in oxazine ring; at 105.31, 121.66, and $139.57 \mathrm{ppm}$ for cyclopentene ring; at 52.50 and $53.35 \mathrm{ppm}$ for arm bound to both imino groups; at 119.38, 121.78-123.30, $126.22,127.90-128.40,133.86-134.10$, and 151.54 ppm for naphthalene group; at $123.88,126.80,131.98$, and $142.62 \mathrm{ppm}$ for phenyl group. In addition, the presence of compound $\mathbf{1 1}$ was further confirmed from mass spectrum which showed a molecular ion at $m / z 547.30$.

Finally, the compound $\mathbf{1 2}$ (Figure 6) was developed by the reaction of $\mathbf{1 1}$ with chloroacetyl chloride using triethylamine as catalyst. The ${ }^{1} \mathrm{H}$ NMR spectrum of $\mathbf{1 2}$ shows signals at $0.68,0.72$, and $0.81 \mathrm{ppm}$ for methyl groups bound to bicyclic ring; at 1.12-1.28, 1.68-1.70, 1.75, and $2.60 \mathrm{ppm}$ for bicyclic ring; at 1.58, 1.71, 1.86, 1.99, 3.64-4.04, and $4.62 \mathrm{ppm}$ for protons involved in cyclobutanone groups; at 1.98 and 2.74 ppm for methyl groups bound to cyclopentene ring; at 2.622.68 and $2.83-2.84 \mathrm{ppm}$ for methylene groups bound to both amino groups; at $4.38 \mathrm{ppm}$ for proton of cyclopentene ring; at 5.16-5.70 ppm for oxazine ring; at 7.09 and $7.38-7.78 \mathrm{ppm}$ for naphthalene group; at 6.90-7.00 and 7.30 ppm for phenyl group. The ${ }^{13} \mathrm{C}$ NMR spectrum of $\mathbf{1 2}$ contains peaks at 13.36, 19.86 , and $20.20 \mathrm{ppm}$ for methyl groups bound to bicyclic ring; at 15.06 and 34.30 methyl groups bound to cyclopentene ring; at 26.40, 36.50, 47.12 and 53.88-61.70 ppm for carbons of bicyclic ring; at 73.10, 100.40 , and $114.66 \mathrm{ppm}$ for cyclopentene ring; at $47.78,82.24,109.20$, and $150.50 \mathrm{ppm}$ for oxazine ring; at 50.66 and $51.40 \mathrm{ppm}$ for methylene groups bound to both 
amino groups; at 32.66, 32.70, 62.92, and 71.00-72.22 ppm for cyclobutanone groups; at 118.60, 121.09-127.90, and 128.40$134.80 \mathrm{ppm}$ for naphthalene group; at 113.70, 119.90, and $128.12-146.86$ ppm for phenyl group; at 202.02 and 203.40 ppm for ketone groups. Finally, the presence of compound 12 was further confirmed from mass spectrum which showed a molecular ion at $m / z 755.30$.

\section{Conclusions}

In in this study two oxazine derivatives were synthesized using some strategies; the methods used offer some advantages such as good yields, simple procedure, low cost, and ease of workup.

\section{Conflict of Interests}

The authors declare that they do not have any financial relations with any of the commercial entities mentioned in the paper that could lead to a conflict of interests.

\section{References}

[1] M. E. Kuehne, E. A. Konpka, and B. F. Lambert, "Steroidal dihydro-1, 3-oxazines as antitumor agents," Journal of Medicinal and Pharmaceutical Chemistry, vol. 5, no. 2, pp. 281-296, 1962.

[2] A. Chaskar, V. Vyavhare, V. Padalkar, K. Phatangare, and H. Deokar, "An environmentally benign one-pot synthesis of 1,2dihydro-1-arylnaphtho[1,2-e] [1,3] oxazine-3-one derivatives catalysed by phosphomolybdic acid," Journal of the Serbian Chemical Society, vol. 76, no. 1, pp. 21-26, 2011.

[3] H. A. Ahangar, G. H. Mahdavinia, K. Marjani, and A. Hafezian, "A one-pot synthesis of 1,2-Dihydro-1-arylnaphtho[1,2-e][1,3] oxazine-3-one derivatives catalyzed by perchloric acid supported on silica $\left(\mathrm{HClO}_{4} / \mathrm{SiO}_{2}\right)$ in the absence of solvent," Journal of the Iranian Chemical Society, vol. 7, no. 3, pp. 770-774, 2010.

[4] F. T. Counter, P. W. Ensminger, D. A. Preston et al., "Synthesis and antimicrobial evaluation of dirithromycin (AS-E 136; LY237216), a new macrolide antibiotic derived from erythromycin," Antimicrobial Agents and Chemotherapy, vol. 35, no. 6, pp. 1116-1126, 1991.

[5] Z. Turgut, E. Pelit, and A. Köycü, "Synthesis of new 1,3-disubstituted-2,3-dihydro-1H-naphth-[1,2e][1,3] oxazines," Molecules, vol. 12, no. 3, pp. 345-352, 2007.

[6] A. H. Kategaonkar, S. S. Sonar, R. U. Pokalwar, A. H. Kategaonkar, B. B. Shingate, and M. S. Shingare, "An efficient syn thesis of 3, 4-dihydro-3-substituted-2H-naphtho[2, 1-e][1,3] oxazine derivatives catalyzed by zirconyl(IV) chloride and evaluation of its biological activities," Bulletin of the Korean Chemical Society, vol. 31, no. 6, pp. 1657-1660, 2010.

[7] A. Mayekar, H. Yathirajan, B. Narayana, B. Sarojini, N. Kumari, and W. T. A. Harrison, "Synthesis and antimicrobial study of new 8-bromo-1, 3-diaryl-2, 3-dihydro-1H-naphtho[1, 2e][1, 3] oxazines," International Journal of Chemistry, vol. 3, no. 1, pp. 74-86, 2011.

[8] V. Verma, K. Singh, D. Kumar et al., "Synthesis, antimicrobial and cytotoxicity study of 1,3-disubstituted- $1 H$-naphtho[1, 2e] $[1,3]$ oxazines," European Journal of Medicinal Chemistry, vol. 56, pp. 195-202, 2012.
[9] L. Figueroa-Valverde, F. Díaz-Cedillo, E. García-Cervera, E. Pool-Gómez, and A. Camacho-Luis, "Design and synthesis of two brucine derivatives," Asian Journal of Chemistry, vol. 25, no. 12, pp. 6783-6786, 2013.

[10] W. J. Burke, R. P. Smith, and C. Weatherbee, "N,N-Bis-(hydroxybenzyl)-amines: synthesis from phenols, formaldehyde and primary amines," Journal of the American Chemical Society, vol. 74, no. 3, pp. 602-605, 1952.

[11] W. J. Burke, M. J. Kolbezen, and C. W. Stephens, "Condensation of naphthols with formaldehyde and primary amines," Journal of the American Chemical Society, vol. 74, no. 14, pp. 3601-3605, 1952.

[12] A. K. Shirayev, I. K. Moiseev, and S. S. Karpeev, "Synthesis and cis/trans isomerism of N-alkyl-1,3-oxathiolane-2-imines," Arkivoc, vol. 2005, no. 4, pp. 199-207, 2005.

[13] D. J.-N. Uppiah, M. G. Bhowon, and S. J. Laulloo, "Solventless synthesis of imines derived from diphenyldisulphide diamine or p-Vanillin," E-Journal of Chemistry, vol. 6, no. 1, pp. S195S200, 2009.

[14] M. M. Hania, "Synthesis of some imines and investigation of their biological activity," E-Journal of Chemistry, vol. 6, no. 3, pp. 629-632, 2009.

[15] L. Figueroa-Valverde, F. Díaz-Cedillo, E. García-Cervera, E. Pool-Gómez, and M. López-Ramos, "Design and Synthesis of $\mathrm{N}$-[2- (2, 3-dimethoxy-strychnidin-10-ylidenamino)-ethyl]succinamic acid 4-allyl-2-methoxy-phenyl ester," Bulgarian Chemical Communication, vol. 45, no. 1, pp. 71-76, 2013.

[16] G. K. Kole, G. K. Tan, and J. J. Vittal, "Anion-controlled stereoselective synthesis of cyclobutane derivatives by solid-state [2+2] cycloaddition reaction of the salts of trans-3-(4-Pyridyl) acrylic acid," Organic Letters, vol. 12, no. 1, pp. 128-131, 2010.

[17] J. Panda and S. Ghosh, "Intramolecular [2+2] photocycloaddition for the direct stereoselective synthesis of cyclobutane fused $\gamma$-lactols," Tetrahedron Letters, vol. 40, no. 36, pp. 6693-6694, 1999.

[18] G. K. Kole, G. K. Tan, and J. J. Vittal, "Role of anions in the synthesis of cyclobutane derivatives via [2+2] cycloaddition reaction in the solid state and their isomerization in solution," Journal of Organic Chemistry, vol. 76, no. 19, pp. 7860-7865, 2011.

[19] Y. Okada, T. Minami, S. Yahiro, and K. Akinaga, "A new synthesis of cyclobutane annelated compounds by the use of a (1cyclobutenyl)triphenylphosphonium salt," Journal of Organic Chemistry, vol. 54, no. 4, pp. 974-977, 1989. 

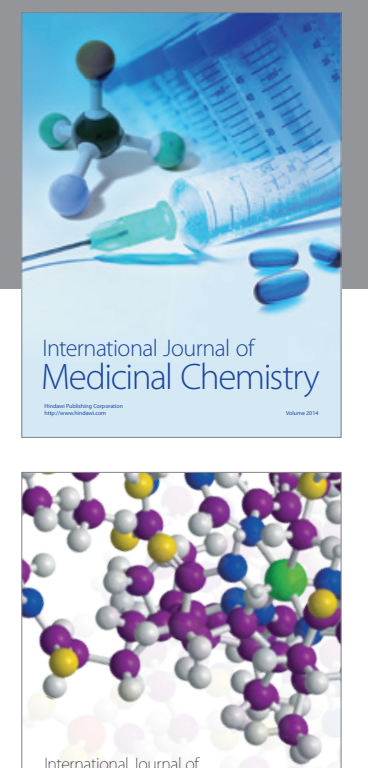

\section{Carbohydrate} Chemistry

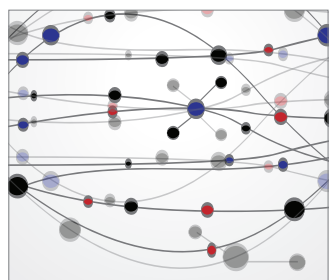

The Scientific World Journal
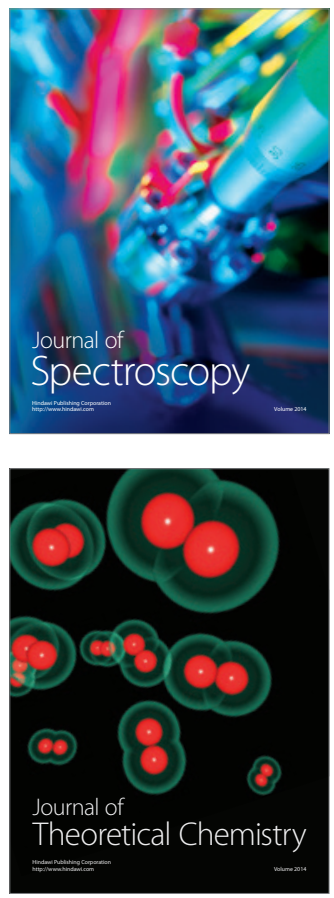
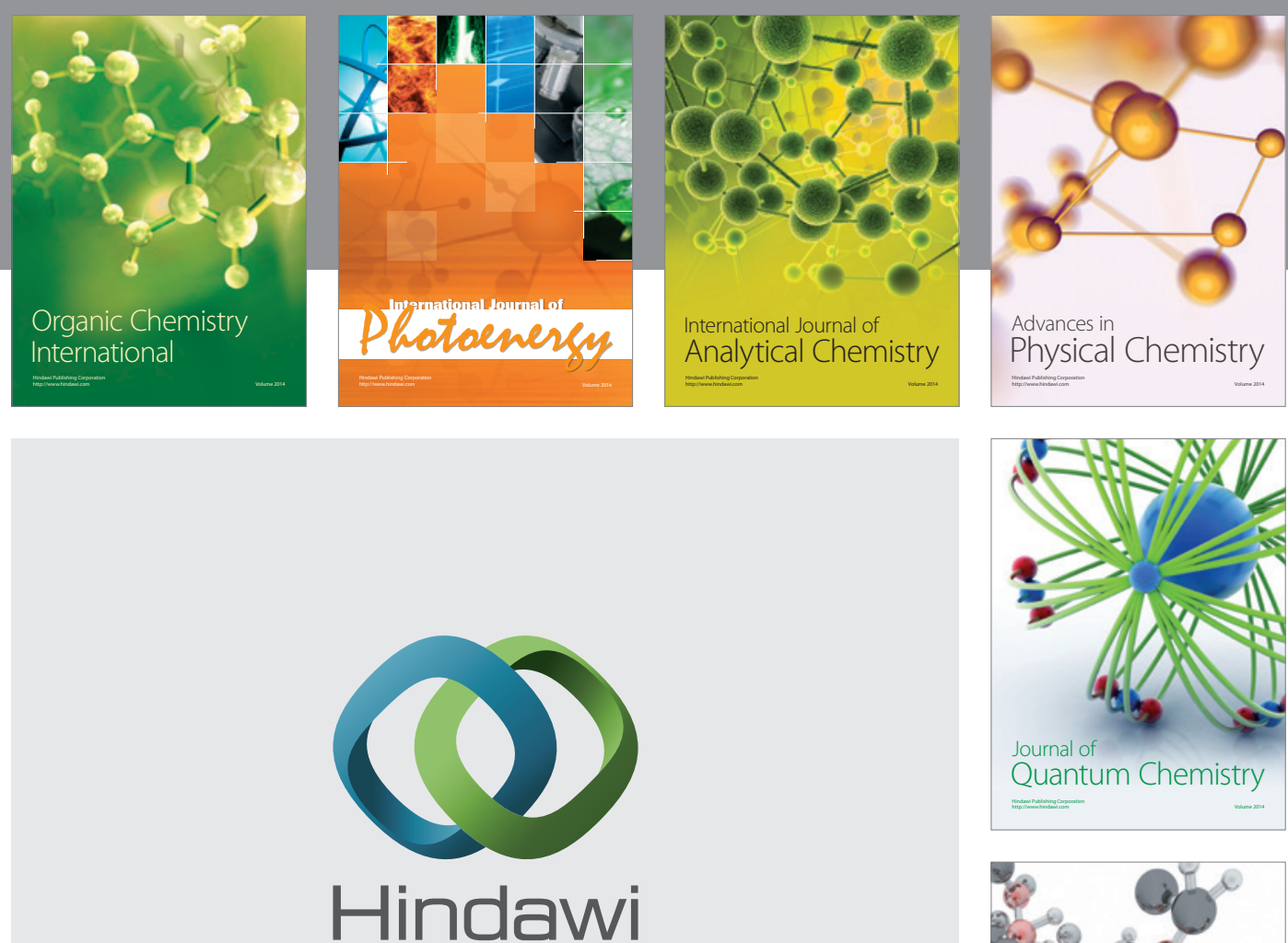

Submit your manuscripts at

http://www.hindawi.com

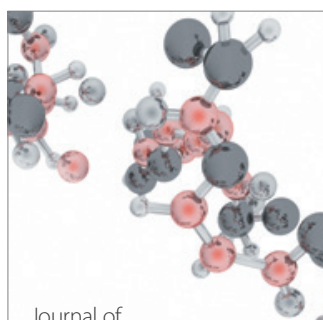

Analytical Methods

in Chemistry

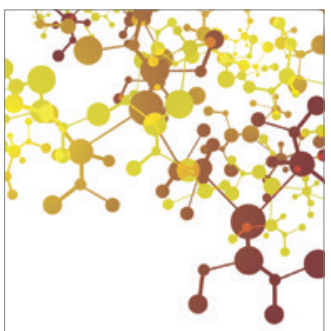

Journal of

Applied Chemistry

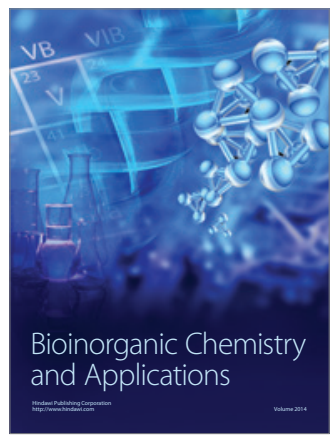

Inorganic Chemistry
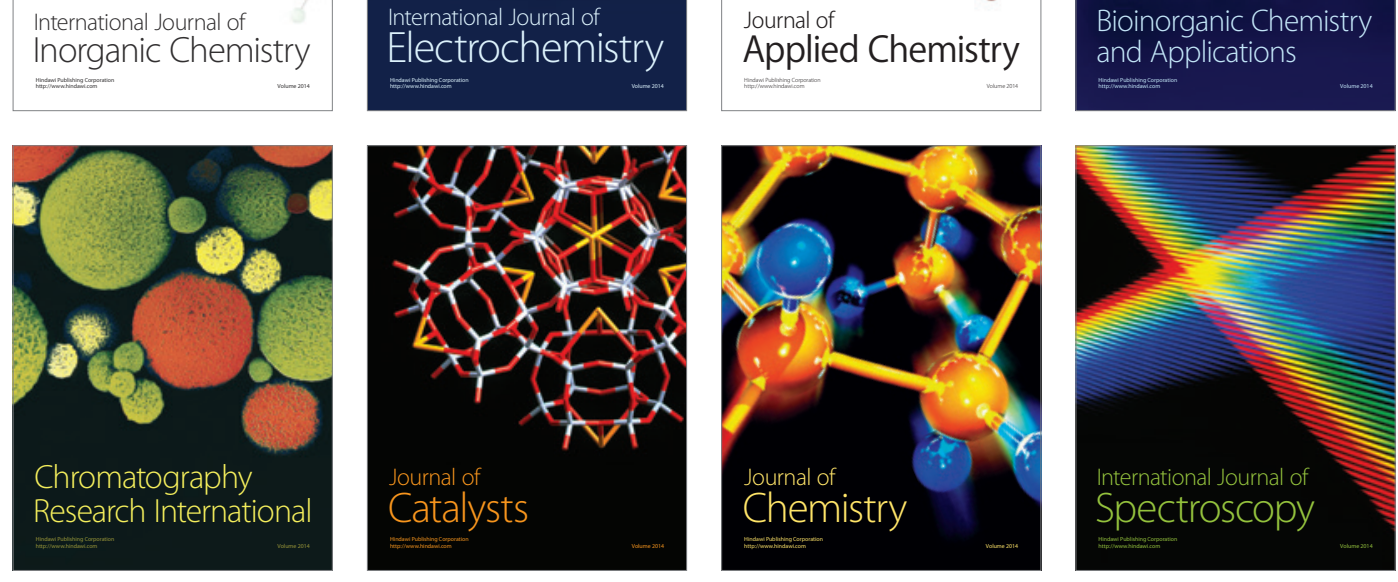